\title{
Sinaloa: ¿cluster agroindustrial o territorio desincrustado?
}

DOI: $10.32870 /$ mycp.v14i41.369

Carlos J. Maya Ambía

\section{Resumen}

$\mathrm{E}$ 1 crecimiento a largo plazo de las exportaciones hortícolas de Sinaloa, dirigidas sobre todo a Estados Unidos, así como su conformación como la región más importante en la producción de hortalizas para exportación, lleva a preguntarnos sobre el impacto regional de dicha actividad. Entre las diversas formas de evaluación de tal impacto existe una que consiste en observar el grado de desarrollo de un conglomerado o cluster de tipo agroindustrial, centrado en torno a la horticultura de exportación. Experiencias de otros países y regiones muestran que la consolidación de clusters constituye un poderoso motor para el desarrollo de las regiones, en particular dentro de la globalización económica.

El propósito del presente estudio es valorar la experiencia de Sinaloa y averiguar si existe o no y hasta qué grado si así fuera, un cluster agroindustrial centrado en la horticultura exportadora. Para ello se analizan, para el caso de Sinaloa, cada uno de los elementos que se han reconocido por los estudiosos del tema, como componentes fundamentales de un cluster. Los resultados obtenidos muestran que aunque en un cierto momento se dieron intentos para la consolidación de un cluster, éstos fueron insuficientes y desembocaron en una situación que denominamos "territorio desincrustado" (disembedded territory) en torno a un cluster incompleto y estancado.

Palabras clave: Agroindustria, cluster, México, Sinaloa.

1. Profesor-Investigador de la Facultad de Ciencias Económicas y Sociales de la Universidad Autónoma de Sinaloa y Profesor Visitante en el Departamento de Estudios del Pacífico de la Universidad de Guadalajara. Correo electrónico: maya@uas.uasnet.mx. 
Abstract

The long-term growth of horticultural exports from Sinaloa mainly to the United States, as well as its consolidation as the most important zone in Mexico in the production of frresh vegetables for export, lead us to question about the regional impact of this economic activity. Among the several ways of evaluation of such an impact, one of them is to observe the level of development of an agro-industrial cluster centered on export horticulture. Experiences all over the world show that the consolidation of clusters is a powerful engine for the development of regions within the economic globalization.

Aim of this research is an evaluation of Sinaloa's experience and to find out if an agroindustrial cluster based on export horticulture exists or not, and how far it is eventually developed. Accordingly, there are analyzed, for Sinaloa's case, each element necesary for the existence of a cluster. The outcomes of this research show that although in the past there were attempts to consolidate a cluster, these were insufficient and they led to a situation that I propose to name of a disembedded territory, based on an incomplete and stagnant cluster.

Keywords: Agroindusty, cluster, Mexico, Sinaloa.

\section{Introducción}

Existen experiencias de regiones especializadas en la producción de ciertos artículos para el mercado nacional o para mercados externos y a partir de esta especialización se han desarrollado clusters o conglomerados, que han dado un impulso al desarrollo regional.

La especialización en productos de exportación ha sido valorada positivamente, sobre todo en el contexto de la globalización neoliberal; una exitosa inserción en los mercados globales sería la clave para promover el desarrollo de las regiones, gracias a la creación de un rico tejido empresarial en el que aparecerían numerosas actividades complementarias a las exportadoras. En una palabra, clusters nacidos de una fuerte orientación de la región a los mercados extranjeros.

Sinaloa es una región ubicada dentro de la esfera de influencia de Estados Unidos; ligada a la economía norteamericana, décadas antes de que se hablara de globalización y con un poderoso flujo de exportaciones hortícolas a dicho país, antes de que se propagara la idea de que los países de menor desarrollo deberían convertirse en proveedores de artículos primarios de alto 
valor, como flores, frutas y hortalizas (Mares, 1991). Sinaloa sigue siendo la entidad hortícola más importante del país, destacando en los cultivos de exportación. En 2007 aportó 27.1\% del valor de la producción de tomate, principal hortaliza exportada. En frutas de exportación también ocupa un lugar destacado, por ejemplo, le corresponde $13.8 \%$ del valor de la producción de mango (INEGI, 2008).

Desde hace mucho tiempo Sinaloa se ubica en la avanzada de la economía agrícola nacional. Primero fue con la caña de azúcar, luego con las hortalizas y ahora también con el maíz. Sin embargo, es una economía rica pero desequilibrada, dominada por su sector primario y con un hipertrofiado sector servicios. Asimismo hay evidencia de la fragilidad de sus procesos de modernización tanto porque se siguen fincando, en gran medida, en el saqueo de sus recursos naturales, en particular el agua, descuidando la sustentabilidad de su economía, como porque han ignorado los aspectos gerenciales de las empresas que permitirían asentar su competitividad sobre bases duraderas. Ello explica en parte el que en una comparación de la dinámica del PIB de todos los estados de la República Mexicana de 1993 a 2004, Sinaloa se encuentre entre los ocho estados con las tasas de crecimiento más bajas, inferiores a $2 \%$; en contraste, las entidades con mejor desempeño tuvieron tasas de crecimiento superiores a 4\% (Dávila, 2008: 59-60).

Debido a su menor velocidad de crecimiento ha venido perdiendo peso relativo en la economía nacional, ya que en 2006 sólo contribuía con 1.89\% del PIB del país, cuando en 1993 esa participación había sido de 2.16\%. Esto indica que la posición de Sinaloa no se encuentra asentada sobre bases sólidas y que su desempeño a largo plazo presenta una tendencia negativa. Si esto es así, hay que preguntarse qué relación existe entre los fenómenos apuntados y la existencia (o ausencia) en Sinaloa de un cluster agroindustrial construido sobre el eje de la horticultura de exportación.

En lo que se refiere al comportamiento del sector agropecuario durante 1993-2006, la tasa de crecimiento medio anual sectorial habría sido para Sinaloa de $1.8 \%$ mientras que para el país de $1.9 \%$. Con toda la importancia que tiene este estado en la producción agrícola del país, aun aquí estuvo por debajo de la media nacional. Esto podría deberse a que sus productos dinámicos no compensaron la pérdida de ingreso que supusieron los bajos precios reales, derivados del proceso de apertura, mientras que sus exportaciones tradicionales, como hortalizas, no mejoraron de manera sustancial a través de un mayor acceso a los mercados externos. Así, se observa que de 1992 a 
2007 las exportaciones hortícolas de México crecieron 188\%, mientras que las de Sinaloa sólo lo hicieron en $13 \%$. En consecuencia, su participación en las exportaciones hortícolas del país bajó de 41\% en el ciclo 1992-93, a 16\% en el ciclo 2007-2008 (Gaxiola y Trujillo, 2010: 58-59).

Debido a lo anterior, el comportamiento del sector agropecuario no ha sido el adecuado para una entidad federativa dotada de una buena base de recursos, naturales o construidos, para su desarrollo agrícola. De cualquier manera, su desempeño fue comparativamente mejor que en la industria y los servicios, donde las tasas promedio anuales fueron de $0.9 \%$ y $2.2 \%$, inferiores a las nacionales, de $3 \%$ y $3.1 \%$ respectivamente.

\section{Planteamiento del problema}

Las ventajas de la concentración de empresas del mismo giro en un determinado territorio fueron señaladas por Marshall bajo el concepto de economías de aglomeración. Posteriormente numerosos autores han enriquecido las ideas originales de Marshall y en la actualidad el concepto de cluster se ha convertido en uno de los más utilizados en la literatura económica.

La OECD ha resumido la discusión de los últimos años sobre el fenómeno expresado por el concepto de cluster en los siguientes términos:

Economists have long noted that specific places specialize in particular activities and that firms engaged in the same or related activities tend to cluster together increasing productivity. While some definitions of clusters lack a spatial dimension, most definitions support the idea that a cluster includes firms and other knowledge-producing agents in a geographically concentrated area with inter-linkages among them. A number of other terms are used by academics and policy makers to describe related phenomena, such as industrial districts, networking, systems of production or, for the broader environment, a regional innovation system (OECD, 2007: 2). ${ }^{2}$

2. "Desde hace mucho tiempo los economistas han notado que lugares específicos se especializan en actividades particulares y que las empresas involucradas en la misma o en actividades relacionadas tienden juntas a formar clusters para incrementar su productividad. Mientras que algunas definiciones de clusters carecen de una dimensión espacial, muchas otras sostienen la idea de que un cluster incluye empresas y otros agentes productores de conocimientos en un área concentrada geográficamente, con encadenamientos entre ellos. Un buen número de otros términos es usado por académicos y diseñadores de políticas para describir fenómenos relacionados, tales como distritos industriales, redes, sistemas de producción o, en un entorno más amplio, sistemas regionales de innovación" (traducción propia). 
Por su parte, el concepto de cluster, conglomerado o aglomeración tiene dos connotaciones. Es una categoría para describir una situación y es una herramienta para promover el desarrollo regional. En el primer sentido se refiere a la concentración geográfica de un grupo de empresas e instituciones interconectadas ubicadas en un determinado territorio. En el segundo, se ha empleado como estrategia de desarrollo para promover la innovación y la coordinación de actividades productivas de los agentes económicos ubicados en un determinado territorio, con el propósito de enfrentar con éxito los desafíos de la globalización económica. Por estas características, de hecho el concepto de cluster viene a ser sinónimo de otros como distrito, bien sea distrito industrial, agroindustrial, agro-comercial, etc., como red o incluso como sistema regional de innovación (véase OECD, 2001).

A partir de estas consideraciones se ha llegado al concepto de cluster o aglomeración industrial. Posteriormente se ha avanzado en su aplicación en la agricultura, pensando que la constitución de clusters agrícolas resultaría de beneficio para el desarrollo regional. Según la OECD (2001), los clusters proporcionan un entorno favorable para la generación, aplicación y difusión de las innovaciones productivas, las cuales, a su vez, impulsan la competitividad y el desarrollo económico.

Teniendo estas ideas en mente, si observamos el comportamiento de la economía de Sinaloa y en particular de la horticultura de exportación, veremos que desde la apertura comercial, el desarrollo económico de Sinaloa ha estado por debajo de la media nacional y, por otra parte, la competitividad de sus principales productos exportados, presenta tendencias decrecientes. Esto nos lleva a la siguiente reflexión. Como bien se sabe, en un área relativamente reducida, se concentran las principales empresas exportadoras de hortalizas frescas, no sólo de Sinaloa, sino de todo México. Si la economía sinaloense ha tenido tan mal desempeño en los últimos años, debemos preguntarnos si este fenómeno podría estar relacionado con un insuficiente desarrollo de un cluster en torno a la horticultura de exportación.

\section{Metodología}

Para tratar de responder esta pregunta primero analizaremos la situación económica de Sinaloa en general y después cada uno de los componentes de un cluster agro-industrial, para profundizar en la situación que éstos presentan en Sinaloa. El siguiente paso será caracterizar conceptualmente los hallazgos 
obtenidos. A continuación buscaremos explicar las causas de la existencia de lo que proponemos denominar un cluster incompleto y estancado. Esta explicación nos llevará a reconocer las limitaciones del concepto de cluster para entender la dinámica de un determinado territorio en el mundo globalizado $y$, por consiguiente, a reconocer la necesidad de ampliar nuestro marco conceptual en términos de la propuesta analítica llamada por Messner (2002) triángulo económico mundial.

\section{Situación económica de Sinaloa}

Sinaloa se ha vinculado a los mercados externos desde hace varios siglos. Durante la Colonia fue a través de la minería. En el siglo XIX fue un importante proveedor de algodón, garbanzo y caña de azúcar. A principios del siglo XX se inicia el cultivo del tomate para ser exportado a Estados Unidos y desde entonces la economía de la entidad ha estado estrechamente vinculada con la de ese país. La construcción de presas en todo el país para impulsar los cultivos de riego benefició a Sinaloa ampliamente, hasta llegar a contar con once, alimentadas por el mismo número de ríos de la entidad.

La Sierra Madre Occidental impone un cierto aislamiento respecto al oriente del país y el suroeste de Estados Unidos, ante la ausencia de vías fluidas para el tráfico de personas y mercancías, situación que aún persiste. Esto ha restringido la posibilidad de beneficiarse de ser un estado con costas y puertos. Además, Sinaloa está situado en una extensa área pero de baja concentración demográfica, distante respecto a los grandes centros de consumo del país. Tiene mercados limitados, pero capacidad de producir excedentes agropecuarios y pesqueros. Hasta cierto punto, los estados del noroeste son competidores entre sí, pues no sólo son adecuados para la agricultura extensiva y de exportación, sino que también cuentan con costas y puertos.

La extensión territorial del estado equivale a $2.9 \%$ del territorio de la nación y sus 2.6 millones de habitantes, representan $2.5 \%$ de la población del país. Además, su tasa de crecimiento poblacional, de $0.49 \%$ para el periodo 2000-2005, estuvo entre las más bajas de México, cuya tasa promedio fue de $1 \%$ para el mismo periodo. Por ello es probable en Sinaloa un crecimiento demográfico negativo a partir del año 2017, debido tanto a la caída de su tasa natural como a la emigración.

Mientras que el ingreso per cápita de Sinaloa en 2006 estaba por debajo de la media nacional, Baja California, Baja California Sur y Sonora superaban 
la media en $30 \%, 24 \%$ y $23 \%$, respectivamente. Por tanto, no sorprende que la emigración de sinaloenses hacia tales entidades federativas y hacia Estados Unidos se haya acelerado. En buena medida ello estuvo vinculado a la crisis de la agricultura y la imposibilidad de que pequeños productores, ejidatarios sobre todo, pudieran sembrar directamente sus tierras, ya que un significativo número fue retirado de las corrientes de crédito, en tanto desaparecían precios y compras garantizados por Conasupo, con lo cual tuvieron que asumir los costos de comercialización. Además, la crisis de la agricultura propició un mayor involucramiento de habitantes rurales en el narcotráfico y otras actividades delictivas.

La estructura económica de Sinaloa muestra una reducción de la participación del sector agropecuario en el PIB estatal de $21.5 \%$ en 1993 , a $12 \%$ en el año 2006, aunque en el último anuario estadístico oficial de la entidad se habla de una participación del sector primario de $13.4 \% .{ }^{3}$ Por su parte, las cifras para la industria han pasado de un modesto $13.2 \%$ en el primero de los años señalados, a un todavía más reducido $12.5 \%$ al final del periodo considerado. En cambio, el heterogéneo sector servicios ha ampliado su presencia, pasando de $65 \%$ a $75.5 \%$ en los años indicados, respectivamente. ${ }^{4}$

Durante la apertura económica, en Sinaloa decrecieron las actividades primarias, que pasaron de representar $21.5 \%$ de la economía del estado en 1993, a 12\% en 2006. Esa pérdida no fue ganada por las actividades secundarias, también con descensos en su participación relativa, de $0.7 \%$, sino por las actividades de servicios, que pasaron de $65.3 \%$ en 1993 a $75.5 \%$ en 2006. En consecuencia, hoy se tiene un sector servicios comparativamente mucho mayor que el del país y un sector industrial subdesarrollado.

En el rubro agrícola, la entidad federativa más importante es Sinaloa, con 9\% del valor de la producción nacional en el periodo 2005-2007, seguida por Michoacán, con $8.8 \%$, Jalisco, con $7.6 \%$ y Veracruz con $7.4 \%$. En esas cuatro entidades federativas se genera casi la tercera parte del PIB agropecuario de México. Sin embargo, dicha importancia relativa de Sinaloa no coincide con su peso en la industria de alimentos del país, ya que ésta ha tendido a establecerse cerca de los grandes centros demográficos. En este rubro Sinaloa se sitúa en la posición 12, entre las 32 entidades federativas del país, con una

3. Instituto Nacional de Estadística y Geografía, Gobierno del Estado de Sinaloa, Anuario Estadístico de Sinaloa 2009, Aguascalientes, 2009.

4. Datos tomados de INEGI, en: http://dgcnesyp.inegi.gob.mx/cgi-win/bdieintsi.exe/NIVM15. 
contribución de $2.2 \%$. Aunque la industria de alimentos ha representado más de 70\% de la industria manufacturera de Sinaloa en el periodo 1993-2006, llegando a $78.6 \%$ en 2006, es relativamente pequeña en el contexto nacional.

Si bien es verdad que debe tenerse presente el efecto multiplicador de las actividades agrícolas sobre las actividades de servicios e industriales, también hasta cierto punto esta estrecha relación explica el pobre desempeño económico de la entidad, pues estas actividades no mantienen una dinámica sostenida propia, sino dependiente de la agricultura. A ello se agrega que ni las actividades industriales ni los servicios se han diversificado para apoyar a la agricultura (véase Trujillo y Gaxiola, 2010).

Al igual que en el caso de la industria manufacturera, la participación del sector agropecuario en el PIB de Sinaloa no ha variado entre 1995 y 2003. Al sector agropecuario corresponde poco más de $21 \%$ y a la industria poco más de $7 \%$. Sin embargo, ambos sectores han presentado bajas tasas de crecimiento e incluso tasas negativas en algunos años dentro del lapso señalado.

La población ocupada en el sector primario representa $21.1 \%$ de la PEA. En el comercio se encuentra ocupada $20.6 \%$, mientras que en la industria manufacturera es sólo 9.9\%. En servicios (restaurantes, alojamiento, servicios profesionales, financieros y corporativos y servicios diversos) está 29.7.3\% (p. 320). ${ }^{5}$

En particular, por lo que respecta a la producción agrícola, $46.2 \%$ de su valor en el año agrícola 2008 correspondió al maíz, 4.9\% a la papa, 5.1\% al frijol, $8.5 \%$ al chile verde, $12.7 \%$ al tomate rojo y $22.6 \%$ al resto de los cultivos. Debe agregarse que la producción hortícola y frutícola de exportación se encuentra concentrada en los siguientes municipios: Guasave, Elota, Navolato, Mocorito, Culiacán, Escuinapa, Rosario, Ahome, El Fuerte y Angostura. ${ }^{6}$

La superficie agrícola se distribuye entre seis distritos. El más grande tiene como cabecera a Los Mochis, con 345 mil hectáreas. Le siguen Culiacán, con 334 mil, Guasave, con 270 mil, Guamúchil, con 194 mil, la Cruz, con 190 mil, y Mazatlán, con 154 mil. Por tanto, la actividad agrícola se sitúa en su mayor parte del centro al norte del estado, donde hay mayor amplitud de valles. En esa extensión territorial se localizan la mayor parte de las siembras de granos. El sur ha mostrado mayor vocación frutícola. La horticultura está en todas

5. Datos tomados de Instituto Nacional de Estadística y Geografía, gobierno del Estado de Sinaloa, Anuario Estadístico de Sinaloa 2009, Aguascalientes, 2009.

6. Datos tomados de INEGI, Anuario de estadísticas por entidad federativa, Aguascalientes 2009. 
las regiones, pero es particularmente importante para Culiacán, donde están los grupos exportadores más fuertes.

En Sinaloa se tenían cuantificados en 1995 a 146 mil productores, número que aumentó a 152 mil en 2006. En esos mismos años, la superficie abierta al cultivo habría pasado de 1.429 millones de hectáreas a 1.487 millones, de manera que la cantidad de hectáreas por productor no se alteró, al mantenerse en 9.8. Por su parte, la superficie media por productor es mayor en la propiedad privada, 18.6, que para el ejido, 8.3 y aunque no hay cambios significativos, se registra una inclinación a que aumente el tamaño de predio en riego mientras se reduce en temporal. ${ }^{7}$

La combinación de un sistema montañoso cerca de áreas costeras relativamente planas y situadas en un área susceptible de ciclones, con un régimen de lluvias corto e intenso en verano, favorece las condiciones adecuadas para la construcción de grandes presas y el ejercicio de una agricultura bajo riego. Las precipitaciones pluviales anuales son en promedio de entre 600 y 800 $\mathrm{mm}$, de manera que el desarrollo agrícola no sería explicable sin las grandes obras de riego. El agua es captada por el sistema de presas en verano para ser utilizada en otoño-invierno, y eventualmente en primavera-verano, dependiendo de su disponibilidad. Las condiciones climáticas en otoño-invierno son benignas, las temperaturas no suelen bajar excesivamente y no es frecuente la ocurrencia de heladas o lluvias intensas. Por todo esto, Sinaloa tiene ventajas en la producción de hortalizas de invierno y ocupa el primer lugar como región exportadora de hortalizas frescas en México, siendo su principal mercado Estados Unidos y marginalmente a Canadá. Como la producción hortícola sinaloense se concentra en el ciclo otoño-invierno, compite con Florida, principal oferente dentro del territorio norteamericano en esa época del año.

\section{Componentes de un cluster agro-industrial}

Los principales componentes de un cluster de tipo agro-industrial pueden representarse en el siguiente diagrama, que resume las opiniones de los autores más relevantes sobre el tema. ${ }^{8}$

7. Datos del gobierno del Estado de Sinaloa, en: http://www.sinaloa.gob.mx.

8. Me he basado en la revisión de la literatura sobre clusters realizada por Bajo (2008). 


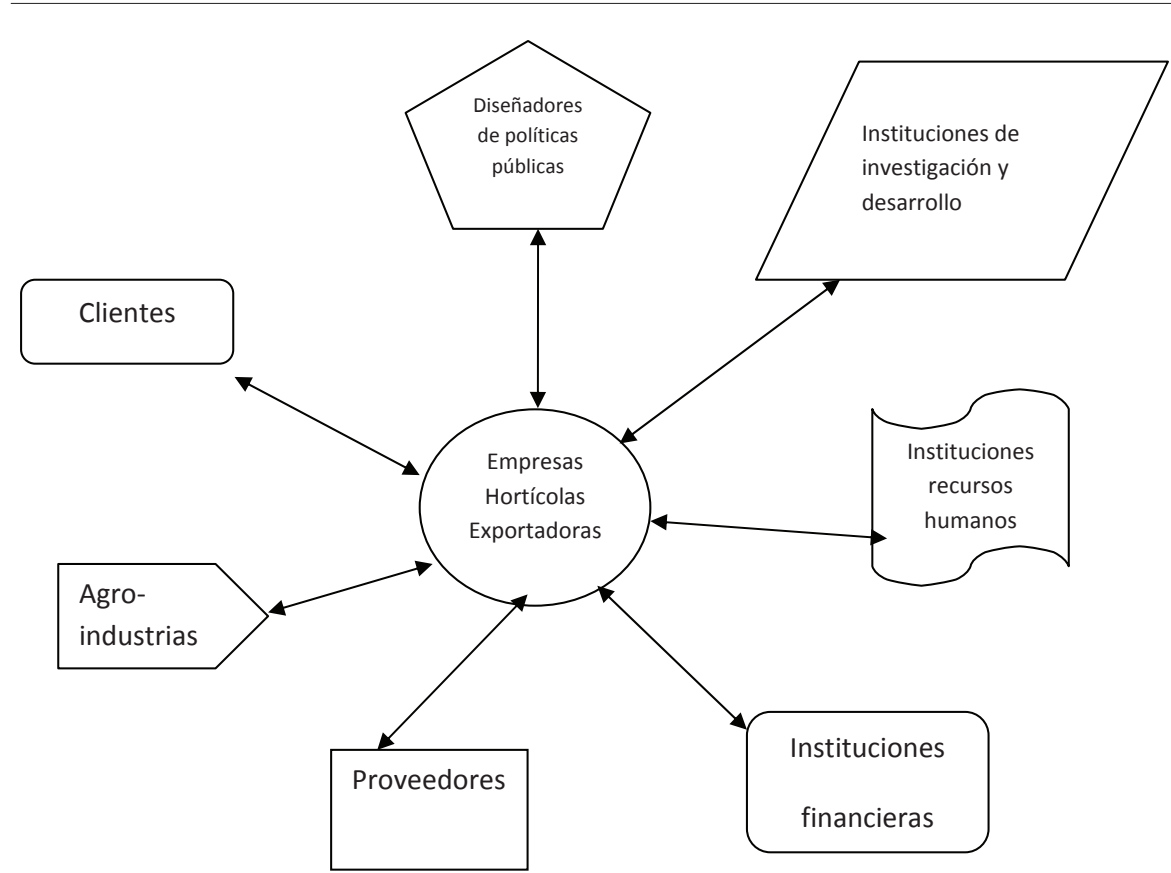

El núcleo del cluster lo constituye un grupo de empresas dedicadas a una misma actividad económica y que están ubicadas en la misma localidad. Esta condición se cumple plenamente en Sinaloa, pero debe precisarse lo siguiente.

El estudio de los clusters industriales revela que su núcleo está conformado por pequeñas y medianas empresas, que de manera individual difícilmente podrían competir con éxito en los mercados mundiales, pero sí al integrarse en un cluster. El referente histórico de estos estudios han sido los casos exitosos de conjuntos de empresas medianas y pequeñas, como las italianas, capaces de desenvolverse combinando competencia y cooperación.

En Sinaloa muchas de las empresas hortícolas líderes en el mercado nacieron como empresas pequeñas o medianas, pero hoy la situación es muy diferente, como lo expresa un especialista de la Comisión para la Investigación y Defensa de las Hortalizas, cuando nos dice que operan alrededor de tres mil empresas hortícolas, ubicándose las de menores dimensiones en el sur de la entidad. De ellas entre 110 y 120 tienen superficies de más de 35 hectáreas y orientan su producción hacia las exportaciones. Sin embargo Bancomext registra sólo 75 empresas hortícolas exportadoras, pues toma como criterio una superficie de siembra mayor (50 hectáreas). 
En el ciclo 2008-2009, los aproximadamente 120 horticultores dedicados a la exportación sembraron 47,624 hectáreas, lo que arroja un promedio de 396 hectáreas por productor. El valor de las exportaciones en dicho ciclo fue de 725 millones de dólares, de tal manera que el promedio por horticultor exportador fue de aproximadamente seis millones de dólares, lo cual indica, por cierto, que la exportación de hortalizas en Sinaloa no se encuentra en manos de pequeñas empresas (Elizalde, 2009). Esto pone de relieve la trascendencia de la estructura del mercado y sus efectos sobre el tipo de competencia desarrollada.

El dominio del mercado sinaloense por empresas de grandes dimensiones, incluso según parámetros mundiales, inhibe la cooperación entre empresas, que pudiera darse si se tratara de unidades de menores dimensiones y que no tuvieran posibilidades de acceder a los mercados externos más que agrupándose y colaborando. Además, las mayores empresas hortícolas en Sinaloa disponen de la tecnología más avanzada en el mundo.

En resumen, no tienen necesidad de colaborar entre ellas. ${ }^{9}$ Es por ello que en Sinaloa, a diferencia de España, no existe una cooperativa de horticultores, pues en su mayoría son tan grandes y poderosos económicamente que no necesitan asociarse para compartir costos de empaque, comercialización, etc., sino que cada empresa tiene sus propias instalaciones y en todo caso, las renta a productores de menor capacidad. ${ }^{10}$ Por otra parte, las empresas hortícolas del Valle de Culiacán que no exportan, son pequeñas y medianas, mientras que las exportadoras son grandes y medianas. ${ }^{11}$

Esta experiencia nos obliga a considerar que no solamente es necesaria la presencia de un buen número de empresas dedicadas a una misma actividad, sino que éstas deberán ser también pequeñas o medianas, para verse en la

9. Agradezco a Raymundo Elizalde, experto de la Comisión para la Investigación y Defensa de las Hortalizas, el haber llamado mi atención sobre la importancia de la estructura del mercado para Sinaloa. Por otra parte, esta opinión contradice la de Arturo Carrillo, quien enfatiza la presencia de la mediana empresa.

10. Carrillo (2009 en Romero y Carrillo, 2009) presenta datos de una encuesta aplicada a 40 empresas hortícolas ubicadas en el Valle de Culiacán, clasificadas por tamaños según los criterios de la Secretaría de Comercio y Fomento Industrial de México en atención al número de personal ocupado. Los resultados arrojan que sólo aparecen dos empresas pequeñas ( $5 \%$ de la muestra), 18 medianas (45\%), y 20 grandes (50\%) (pp. 382 ss.). El 15\% de las empresas encuestadas se establecieron entre 1981 y 1990 y 67.5\% lo hizo a partir de 1991.

11. Para tener un punto de comparación cabe recordar que en promedio cada productor sinaloense tiene 9.8 hectáreas, siendo el promedio 18.6 hectáreas tratándose de propiedad privada y 8.3 hectáreas para los ejidos. 
necesidad de cooperar y así tener la posibilidad de acceder a los mercados internacionales. Esto no quiere decir que una vez consolidado el cluster, sus empresas puedan crecer y elevar sus escalas de operaciones. De hecho, éste puede ser uno de los objetivos para la construcción del cluster, pero cuando ya antes de la conformación del cluster existen empresas de gran escala y/o marcadas diferencias de tamaño entre los integrantes del mercado, no se cumple la primera condición para la formación de un cluster.

El siguiente elemento son las políticas públicas favorables a la constitución de un cluster. Tanto las experiencias históricas de clusters exitosos, como los proyectos de formación de nuevos clusters revelan que las diferentes instancias de gobierno (local, regional, nacional) desempeñan un papel central. ${ }^{12}$ En Sinaloa tanto los gobiernos estatales como nacionales impulsaron en gran escala la horticultura mediante la creación de la infraestructura hidráulica requerida por esta actividad. En la actualidad existen en Sinaloa 11 presas, la mayor parte de ellas construidas en la segunda mitad del siglo pasado. Sin embargo, existe un gran rezago en otros renglones de la infraestructura. Por ejemplo, un ferrocarril obsoleto y en pésimas condiciones de operación, carreteras en mal estado, sobre todo en la época de lluvias. Además, los horticultores nunca disfrutaron directamente de los subsidios que beneficiaron durante años a los productores de granos básicos, como el maíz. Los horticultores tampoco se beneficiaron de Fertimex, pues la mayor parte de sus fertilizantes no eran producidos por dicha paraestatal. Todo esto apunta hacia un gran vacío en el modelo de un cluster por lo que concierne a las políticas públicas.

El tercer componente lo constituyen las instituciones donde se realizan actividades de investigación y desarrollo. Los estudios sobre clusters exitosos destacan la activa participación de instituciones educativas, donde se realiza investigación relacionada con las actividades económicas de las empresas núcleo del cluster. En Sinaloa lo que ocurre ha sido investigado por Bajo (2008) a través de una encuesta aplicada a fines de 2007 y principios de 2008 a 25 empresas hortícolas exportadoras ubicadas en Sinaloa (de ellas 15 en el centro del estado, siete en el norte y tres en el sur), de un universo de 75 empresas registradas por el Banco de Comercio Exterior.

El origen de las numerosas innovaciones realizadas en los ámbitos de producción, empaque y administración, es extranjero en $75 \%, 15 \%$ nacionaly

12. Para México véase por ejemplo Dussel (2003) y Sagarpa/Fidesur (2009); para Indonesia véase Mandang y Wiryokusumo (s/d) y para otros países Ketels (2003). 
$10 \%$ desarrollado por la propia empresa. Aquí interesa destacar que $65 \%$ de los encuestados dijo desconocer las innovaciones realizadas en las instituciones de educación superior y la debilidad de la colaboración universidad-empresa se expresa en el hecho de que la mayoría (75\%) de las empresas encuestadas no ha suscrito convenio alguno con dichas instituciones. Igualmente débil es la participación del gobierno en los procesos de innovación, pues sólo 20\% de los encuestados respondieron que era aceptable, sin ser positiva; para el resto de los entrevistados era nula, baja o intermedia.

Por todo lo anterior, Bajo (2008: 20) concluye que "es muy poca la importancia que le otorgan las empresas hortícolas del estado de Sinaloa a la participación del gobierno y las instituciones educativas para la promoción, apoyo e impulso para el desarrollo de las innovaciones" (p. 20). Esto indica que el tercer componente del modelo de cluster está ausente o es tan débil que su presencia es irrelevante para el desarrollo de la horticultura en Sinaloa. Por otra parte, tratándose de horticultura es conocido que el eje de las investigaciones es la genética aplicada a los procesos de obtención de semillas mejoradas que produzcan frutos de larga vida de anaquel y resistentes a las plagas de la región.

Esta investigación se realiza por un reducido grupo de grandes empresas transnacionales ubicadas en los países desarrollados (Aventis, BASF, Bayer, Dow AgroSciences, DuPont, FMC, Monsanto y Syngenta. Véase CropLife, 2002: 17). Algunas de estas empresas o sus filiales cuentan con plantas en Culiacán, como Zeraim, Rogers y usAgriseeds, donde se realizan pruebas con las semillas desarrolladas por sus genetistas en Israel, EU o Europa, ya que en México, incluso por cuestiones legales, todavía no es posible la producción de semillas. ${ }^{13}$

El siguiente componente son las instituciones formadoras de recursos humanos para las empresas del núcleo del cluster. En Sinaloa destacan dos instituciones cuyos egresados están estrechamente relacionados con la horticultura: la Escuela de Agronomía de la Universidad Autónoma de Sinaloa y el Centro de Investigación en Alimentación y Desarrollo. Existen otros profesionistas que podrían apoyar a las empresas, como son biólogos, ad-

13. En particular en el caso del tomate, la principal hortaliza de exportación de México y de Sinaloa, las empresas productoras de semillas presentes en el mercado son: Zeraim Gedera, Syngenta Seeds/Rogers, Enza Zaden, Harris Moran, De Ruiter Seeds/Monsanto, Molina Seed, Western Seed/Monsanto, Seminis/Monsanto, Sakata Seed, por mencionar las más relevantes (Gómez, 2010: 159-174). 
ministradores de empresas y otros. Sin embargo, según los empresarios, los egresados de las instituciones de educación superior en general carecen de los conocimientos requeridos por ellos y, además, están ausentes los vínculos universidad-empresa que podrían servir para llegar a un mayor entendimiento de los requerimientos profesionales de la actividad hortícola. Sin duda existen las bases para una colaboración entre ambos sectores, pero no se ha desarrollado por causas imposibles de abordar en este trabajo. En suma, el cuarto componente del cluster está presente, pero no con la fuerza deseable y necesaria.

Las instituciones financieras son el quinto componente. Estas funciones pueden desempeñarlas los gobiernos en sus distintos niveles (local, estatal, nacional), o empresas privadas, como los bancos o clientes de los horticultores o incluso las mismas empresas hortícolas. La experiencia de Sinaloa ha sido analizada con detalle por Zazueta (2006), quien apunta que la participación del sector agropecuario en el PIB del estado no guarda proporción con el crédito que la banca comercial ha destinado a esta actividad productiva en el estado y, además, se observa una tendencia a la baja. Por ejemplo en 1995, 23.2\% del importe total del crédito colocado se destinó al sector agropecuario, pero en 2004 bajó a 19.7\% (Zazueta, 2006: 126).

Medina (2006) estima una cifra más baja, pues considera que en el año 2004 sólo 6\% de los créditos otorgados por la banca comercial en Sinaloa se dedicaron al sector agropecuario. Por otra parte, los créditos a la industria manufacturera ya eran reducidos en 1995 (9.35\%) y lo fueron más al final del periodo observado (5.61\%). Esto indica un débil apoyo a las actividades hortícolas y uno aun menor a las industriales, incluyendo a la industria procesadora de alimentos, uno de los componentes del cluster analizado.

Ante la falta de créditos del gobierno y de la banca, las empresas hortícolas tienen dos opciones. Una es el autofinanciamiento y la otra, muy frecuente en Sinaloa, es el crédito proporcionado por sus clientes. La encuesta aplicada por Carrillo (2009) a 40 empresas hortícolas en Sinaloa confirma esta situación. Sus resultados arrojan que la fuente más importante de financiamiento son las distribuidoras estadounidenses (42\%), le sigue el autofinanciamiento (32.5\%) y en tercer lugar la banca (20\%). Estos hechos permiten concluir que el crédito institucional en Sinaloa ha estado ausente.

El sexto componente es la presencia en la localidad de proveedores comunes de insumos y servicios. En la horticultura los insumos y servicios esenciales son semillas, agroquímicos, maquinaria especializada y, de creciente 
relevancia en la actualidad, los invernaderos. Las semillas son importadas y en Sinaloa las veinte más grandes empresas transnacionales productoras de semillas cuentan con oficinas o con distribuidores. ${ }^{14}$ Los agroquímicos, de acuerdo con el informe anual 2008 de la Asociación Mexicana de la Industria Fitosanitaria (AMIFAC, 2008), proceden de doce empresas dedicadas preponderantemente a actividades de investigación para la fabricación de productos fitosanitarios.

Con una sola excepción, son grandes empresas transnacionales. Además, muchas de ellas, directamente o a través de subsidiarias, se dedican también a la producción de semillas mejoradas. De manera complementaria se encuentran otras 22 empresas, dedicadas a la maquila, distribución y comercialización de productos fitosanitarios y además operan otras 18 firmas dedicadas sólo a la distribución y comercialización. En estas categorías sí se encuentran numerosas empresas mexicanas (Amifac, 2008: 5).

Con respecto a la maquinaria especializada para la horticultura, recuérdese que en México no existe una industria propia, sino que está dominada por marcas extranjeras, cuyos productos se distribuyen por empresas filiales o bien mexicanas, con oficinas en Sinaloa, por ejemplo, John Deere, Massey Ferguson, Sumitomo, Komatsu, McCormick, Yto, por mencionar las más conocidas.

Finalmente, el cultivo protegido todavía no es mayoritario en Sinaloa, pero va ganando terreno. En el ciclo 1999-2000 sólo existían 82 hectáreas bajo este sistema y en el ciclo 2008-2009 ya fueron 2,873 hectáreas, correspondiendo $46 \%$ de ellas a distintas variedades de tomate (CIDH, 2009). La tecnología procede de España, Israel, Francia, EU e incipientemente es nacional. Todas estas empresas tienen establecimientos o representaciones en Sinaloa.

Lo arriba apuntado permite afirmar que el sexto componente del cluster sí tiene fuerte presencia en Sinaloa, pero se trata de un componente externo, lo cual es relevante desde la perspectiva territorial y de desarrollo regional, pues indica que no se está creando tecnología propia.

El séptimo elemento es la presencia de un grupo de empresas dedicadas a la transformación industrial de los productos hortícolas. La industria agroalimentaria en Sinaloa ha sido históricamente débil, como su sector industrial

14. Información proporcionada por la CIDH. 
sinaloense en general (Retamoza, 1994; Figueroa, 2003). ${ }^{15}$ Los intentos de impulso a la industrialización por parte de los gobiernos estatales ocurridos antes de los años setenta fueron de corta vida y nulos resultados. Después hubo un impulso más serio del gobierno estatal, pero no encontró la respuesta esperada por parte de los empresarios.

En la década de 1980 hubo nuevos intentos pero poco funcionales. Las iniciativas de los años noventa se encaminaron hacia la instalación de maquiladoras en Sinaloa, pero incluso aquí las políticas fueron insuficientes e ineficientes, debido en parte a que cada nuevo gobierno estatal tiene distintas prioridades (Retamoza, 1994: 186, 187, 196). En este contexto de industrialización frustrada se ubican las empresas procesadoras de alimentos; la parte mayoritaria del sector industrial de la entidad. Aunque actualmente se registran 2,301 unidades en la industria de alimentos y bebidas, sólo 23 corresponden a procesamiento y envasado de frutas y verduras.

Sus productos son sobre todo pasta de tomate, tomates deshidratados, pasta de mango, salsa picante, verduras enlatadas o congeladas y chiles deshidratados. ${ }^{16}$ Sin embargo, esta industria realiza una mínima aportación al PIB estatal, alrededor de 5\%, mientras que el sector agropecuario tiene una participación de 13.4\%, según datos para 2007. En los años 2008 y 2009 el valor de la producción industrial representó menos de la mitad del valor de la producción hortícola y sólo alrededor de $37 \%$ del valor de las exportaciones en fresco. ${ }^{17}$

Sobre la evolución de la industria alimentaria en Sinaloa ilustran 180 encuestas aplicadas por Espinoza (2002) a empresarios. Aunque en la década de 1970 empezaron a crearse establecimientos en la agroindustria sinaloense, casi la mitad de las empresas encuestadas (44.9\%) inició sus operaciones en la década de 1990 y en la década anterior lo hizo $24.5 \%$ de ellas. Por lo tanto, $69.4 \%$ de las empresas estudiadas inició sus actividades en condiciones desfavorables debido a la crisis que padecía México. Estas empresas se crearon en

15. La participación porcentual de la industria manufacturera en el PIB estatal de Sinaloa ha caído de $12 \%$ en 1970 a menos de $8 \%$ a lo largo de la década de 1990 . Por otra parte, su participación en el producto industrial nacional descendió de $1.2 \%$ en 1970 a $0.8 \%$ hacia fines de la década de los noventa, sin que posteriormente haya ocurrido una recuperación (Figueroa, 2003: 195, 196, 197).

16. Información directa proporcionada por el Departamento de Agroindustria del gobierno del estado de Sinaloa. Agradezco aquí el valioso apoyo del Ing. Diego Mojardín, director de dicho departamento.

17. Datos del gobierno del estado de Sinaloa 2009 y cálculos con base en datos de la CIDH. 
respuesta a una política económica del gobierno federal junto con una política estatal destinadas a generar empleos fuera de los sectores tradicionales. Sin embargo, estas empresas se han caracterizado por una reducida diversidad y poca integración con otras industrias y han mantenido una baja participación en el PIB estatal en comparación con la situación de la agroindustria nacional y esta débil participación tiende incluso a disminuir.

Estos establecimientos son de bajo nivel tecnológico, alta intensidad de mano de obra, de reducida escala (micro y pequeñas empresas en su mayoría) y se concentran en cinco municipios: $55.6 \%$ opera en Culiacán, $16.1 \%$ en Los Mochis, $14.4 \%$ en Mazatlán, $10.6 \%$ en Guasave y $13.3 \%$ en El Rosario (Espinoza, 2002: 249-251). ${ }^{18}$ Además, de las empresas encuestadas sólo $1.7 \%$ se dedicaba al procesamiento del tomate; la mayoría se dedicaba a la producción de productos de harina de trigo y sus derivados, carnes, maíz o productos del mar (Espinoza, 2002: 254)

Otro aspecto de interés es el origen social de los industriales entrevistados. Casi la mitad (43.1\%) de ellos señaló que tenían padres comerciantes, 18\% descendía de empleados, $14.4 \%$ de agricultores y sólo $9 \%$ era de familia de industriales. Los demás venían de familias de ganaderos, obreros o pescadores (Espinoza, 2002: 257). Si al origen social aunamos los antecedentes laborales de los industriales entrevistados (30.8\% eran comerciantes, $22.7 \%$ empleados, $5.8 \%$ agricultores, $3.5 \%$ ganaderos, $2.3 \%$ banqueros y sólo $16.3 \%$ ya eran industriales), se completa el cuadro, cuya característica es la débil tradición industrial y el gran peso de los comerciantes y otros que no se caracterizan por un moderno espíritu empresarial (Espinoza, 2002: 258).

A cuatro décadas de su nacimiento, la debilidad actual de la industria procesadora de alimentos en Sinaloa ha sido reconocida por el Consejo para el Desarrollo de Sinaloa (Codesin). ${ }^{19}$ De acuerdo con Medina (2006), director de Estudios Económicos del mencionado consejo, no existe una integración del sector primario al sector industrial y la industria alimentaria en Sinaloa presenta un magro desarrollo; además, Sinaloa enfrenta la competencia de otros estados de la república con una significativa producción industrial de alimentos. Así, Sinaloa ocupa la posición 12 (de 32) en la producción nacional

18. También Codesin (Medina, 2006) señala la fuerte concentración geográfica de la industria alimentaria en Sinaloa, pues $90.3 \%$ de las pocas empresas de esta rama se concentran en sólo tres municipios: Culiacán, Mazatlán y Ahome.

19. Organismo integrado por empresarios, ciudadanos y funcionarios públicos, creado en 1996 con el propósito de contribuir al desarrollo económico de la entidad. 
de alimentos industrializados, aportando sólo $2.3 \%$ del valor y $1.9 \%$ de las unidades económicas del ramo en el país. Los datos para el lapso 1994-2004 muestran que a tres cuartas partes de la producción primaria estatal no se les agrega valor.

Por todo lo anterior se concluye que el peso de la escasamente diversificada industria alimentaria en la entidad está muy por debajo de su capacidad y que la vinculación entre los sectores primario y secundario está muy lejos del potencial necesario para desarrollar una mayor y más competitiva industria de alimentos. En conclusión, el séptimo componente de un cluster agro-industrial en el caso de Sinaloa es tan débil que de hecho está ausente. ${ }^{20}$

Un último componente es la presencia de un grupo de clientes comunes, localizados en el territorio del cluster o fuera de él. En este caso los clientes directos de las empresas hortícolas que operan en Sinaloa son las empresas distribuidoras ubicadas en Nogales, Arizona y los indirectos o finales comprenden una amplia gama de compradores, fundamentalmente en el este de EU, pero no sólo en esa región. En este caso, lo relevante para el funcionamiento de la horticultura de exportación de Sinaloa es la concentración de empresas distribuidoras en el punto fronterizo más cercano a la región productora.

Por lo anterior, sin duda está presente el último factor necesario para un cluster, pero este factor asume, para el caso de Sinaloa, particular trascendencia, ya que son las empresas distribuidoras localizadas en Nogales, Arizona, las que de hecho permiten la existencia de la horticultura de exportación en Sinaloa. Por una parte, en ocasiones han proporcionado créditos a los horticultores, pero su función toral ha sido introducir los productos de los horticultores sinaloenses al mercado estadounidense. Sin embargo, la historia de las relaciones entre empresas distribuidoras y empresas productoras no ha estado exenta de fricciones. Esto motivó que las compañías hortícolas con mayores recursos económicos establecieran sus propias distribuidoras en Estados Unidos. ${ }^{21}$

20. Por esta razón algunos estudiosos han propuesto hablar, refiriéndose a Sinaloa, no de un distrito agro-industrial, sino de un distrito agro-comercial (Carrillo, 2009; Frías, 2009). Sin embargo, la introducción de este concepto sólo toma en cuenta la ausencia de la fase de industrialización de los productos hortícolas, pero no explica la carencia de los demás factores que estamos tomando en cuenta.

21. Para mayores detalles véase López (2008). 


\section{Caracterización de la situación de Sinaloa}

Para Trujillo y Gaxiola (2010) el bajo desempeño de la economía sinaloense se debe, entre otras cosas, al pobre desempeño de la agricultura y a que tanto la endeble industria como el extenso sector servicios, en buena parte dependen de la agricultura. En consecuencia, mientras que en los años sesenta la agricultura impulsó al resto de las actividades económicas en la entidad, ahora, en particular desde la apertura comercial hacia mediados de los años ochenta, se ha convertido en un lastre toda la economía. De ser correcta esta interpretación, entonces podría pensarse en la existencia de dos tipos de clusters: uno dinámico, basado en encadenamientos productivos más o menos fuertes, y otro estancado, pasivo o debilitante, basado en encadenamientos improductivos.

Así, el pobre desempeño de Sinaloa en las últimas dos décadas podría explicarse por la presencia de este tipo de cluster. También habría que ver si dicho cluster es completo o no, pues podría carecer de algunos encadenamientos productivos y los que estén pesando sean los improductivos. En una situación de cluster incompleto o trunco, en Sinaloa existiría un tejido empresarial de baja densidad, sobre todo en los nodos que podrían dinamizar el sistema (instituciones financieras, instituciones educativas y de investigación) y de mayor densidad en nodos que están actuando como lastres, como el hipertrofiado sector servicios.

Por otra parte debe considerarse la forma en que el cluster ha respondido a las exigencias de los estándares globales. Destacaremos dos de ellos: uno son las condiciones sociales de los jornaleros agrícolas y, el otro, los efectos sobre el medio ambiente. Desde la perspectiva del desarrollo regional y territorial es deseable la conformación de clusters pues contribuyen al bienestar general de la población y uno de sus segmentos más relevantes son los trabajadores, imprescindibles en las actividades hortícolas.

En Sinaloa, las tareas de corte y recolección han recaído tradicionalmente sobre jornaleros migrantes. Durante la época de cosecha, en los meses de invierno fundamentalmente, pero con variaciones temporales según el producto específico, llegan alrededor de 300 mil personas procedentes de Oaxaca, Guerrero y Chiapas y ocasionalmente de Veracruz y Zacatecas. La extrema pobreza de los trabajadores migrantes los obliga año con año a salir de sus pueblos, donde las condiciones de subsistencia son cada día peores. Vienen a Sinaloa acompañados de su esposa e hijos, quienes participan activamente en 
las labores agrícolas. Sobre sus condiciones de vida se ha discutido y se sigue discutiendo ampliamente y las opiniones no siempre coinciden.

Desde la óptica de las ONG internacionales se presentan violaciones a los derechos humanos y los empresarios no tienen una opinión única. Para algunos las condiciones de los jornaleros son adecuadas y los salarios justos, aunque las condiciones reales entre empresas varían enormemente. Como se les paga a destajo, aspiran a recolectar la mayor cantidad posible de frutos, incorporando a toda la familia, incluyendo niños de 10 o 12 años. Por ello los mismos jornaleros insisten en que se les permita trabajar a sus niños. Pero, como algunos empresarios comprometidos socialmente sostienen, si el salario pagado es suficiente, el trabajador no necesitará el apoyo de los menores y éstos estarán en condiciones de asistir a la escuela, misma que la empresa está obligada a proporcionar a los hijos de sus trabajadores. ${ }^{22}$ Aquí también las condiciones, calidad y eficiencia de tales escuelas y del personal docente, varían de empresa a empresa. Es por ello que no puede decirse que todas las empresas hortícolas de Sinaloa proporcionan a sus trabajadores condiciones laborales dignas y justas, si bien hay ejemplos excepcionales, pero que por serlo sólo resaltan la magnitud del problema en su conjunto. ${ }^{23}$

Por otra parte, son innegables los daños causados tanto directamente a los trabajadores agrícolas, como indirectamente a la población de todo el territorio sinaloense, debido al uso poco cuidadoso del agua y al abuso de agroquímicos, y en general sustancias tóxicas en la horticultura. ${ }^{24}$ Sobre el tema del agua me remito a las investigaciones de Díaz $(2004,2007)$, quien en contra de quienes consideran a Sinaloa como una entidad rica en recursos naturales y que sus once ríos y numerosas presas son garantía de una abundancia sin fin, aporta información y argumentos alarmantes sobre el inminente agotamiento de los recursos naturales de la entidad.

Este autor subraya el fenómeno de la pobreza hídrica de Sinaloa, resultado de cien años de inserción de la horticultura sinaloense en el mercado de Estados Unidos, es decir, un largo periodo caracterizado por la exportación de agua incorporada a una serie de productos que la exigen en enormes cantida-

22. Entrevista personal al ingeniero Eduardo Leyson, el día 7 de junio de 2010.

23. El tema ha sido ampliamente investigado. Véase Guerra (1998), Grammont y Lara (2004), Posadas (2009), Beraud et al. (2008). Véase también la evaluación externa del Programa de Atención de Jornaleros Agrícolas coordinado por Yúnez-Naude (2005). En particular sobre el trabajo infantil véase Sánchez (2000).

24. Para un testimonio reciente es ilustrativo el video de Halkin (2008). 
des para su crecimiento. La exitosa incursión de los horticultores sinaloenses en el mercado mundial no hubiera sido posible sin la disposición del recurso hídrico, hoy en peligro de agotamiento.

Asimismo, Díaz vincula el abuso y mal uso del precioso líquido con el deterioro de la pesca y con las alteraciones climatológicas, derivadas también de otros factores, como la industrialización de la agricultura, la automovilización de las ciudades y el crecimiento urbano caótico y depredador. Así, inviernos más fríos y veranos más calurosos, sequías alternadas con tormentas fuera de temporada, vienen a conformar un escenario en el que poco o nada significativo se hace por los distintos niveles de gobierno para revertir el curso de los acontecimientos, que avanzan hacia la destrucción de las fuentes mismas de la vida.

Por lo que toca al deterioro ambiental, me remito al estudio de Beraud et al. (2008), donde queda claro que existen una serie de plaguicidas prohibidos en otros países, pero usados todavía en México, como son lindano, DDT, aldrin, metoxiclor y otros. Asimismo, restos de plaguicidas organofosforados se han detectado tanto en aguas como en suelos de Sinaloa y restos de plaguicidas organoclorados se han identificado en la sangre de los jornaleros agrícolas. De la misma manera hay evidencia de prolongadas exposiciones de los trabajadores a plaguicidas organofosforados, dañinos para la salud (Beraud et al., 2008: 165-171). Por consiguiente, algunas prácticas asociadas a la horticultura de exportación en Sinaloa no están contribuyendo al bienestar de los habitantes del territorio y además están dañando el ecosistema. Esto contradice el propósito de la formación de clusters, que es el desarrollo económico y social de sus territorios, lo cual implica en primer lugar, bienestar de sus habitantes y calidad de su entorno.

$\mathrm{Si}$ a lo anterior agregamos el componente social, caracterizado por precarias condiciones de trabajo de los jornaleros migrantes y si añadimos los frecuentes casos de trabajo infantil, entonces tenemos elementos suficientes para calificar a Sinaloa como un territorio desincrustado de la sociedad, en tanto que le está resultando disfuncional. ${ }^{25}$

25. Refiriéndose a Andalucía, Silva (2004) habla de un territorio disfuncional. 


\section{Tipología de clusters según su conectividad y dinamismo}

Sobre la base de los estudios empíricos sobre clusters y en particular de lo anteriormente expuesto con relación a Sinaloa, podemos identificar la necesidad de tomar en cuenta por lo menos dos dimensiones del cluster. Una es su nivel de conectividad y la otra su grado de dinamismo económico. Así, tendríamos hipotéticamente los siguientes cuatro tipos de clusters.

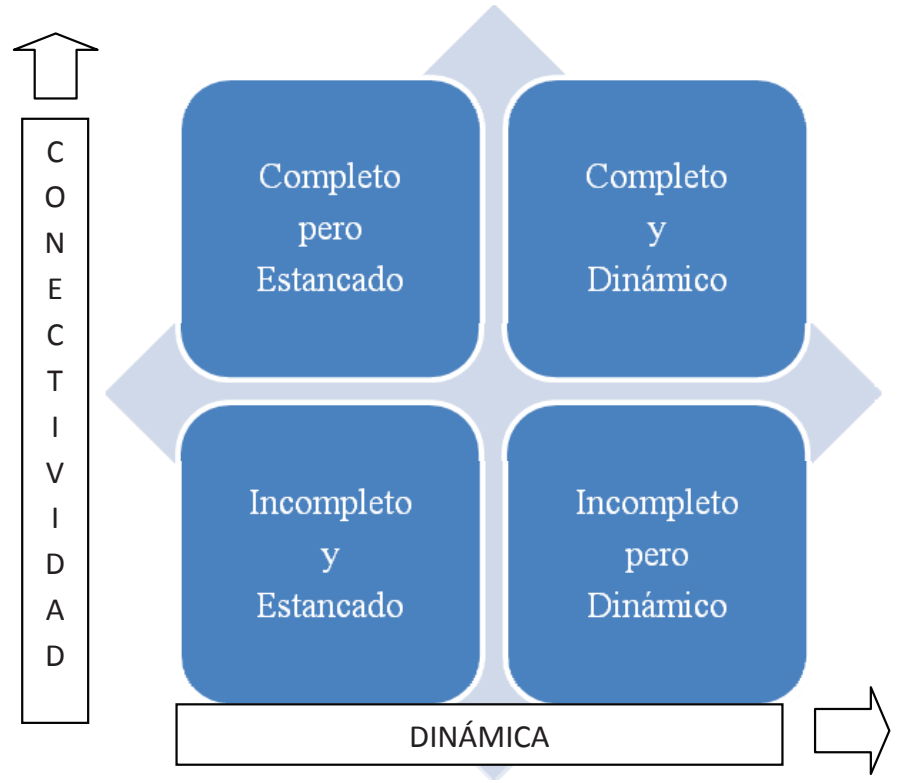

El grado de conectividad de un cluster depende del número y de la magnitud de las interrelaciones establecidas entre los ocho agentes que deben integrarlo. Si alguno de ellos no existe o tiene una escasa articulación con los demás agentes, hablaremos de una baja conectividad. Por el contrario, si están presentes todos los agentes y además están fuertemente interrelacionados, se hablará de un cluster de alta conectividad. Desde luego pueden presentarse numerosas situaciones intermedias y las conexiones entre los agentes, para ser consideradas como fuertes, no solamente deben existir sino también ser canales de transacciones frecuentes y de alto valor.

Por otra parte, un cluster puede ser más o menos dinámico, permanecer estancado o mostrar un franco retroceso. El criterio para evaluar su dinamismo será su aportación a la riqueza real del territorio y del país; no sólo al PIB, 
sino a la calidad de vida, tanto social como medioambiental. Por otra parte, la dinámica del cluster no depende sólo de factores regionales sino de su integración en las cadenas globales de valor y en las redes de estándares globales (véase Messner, 2002). De acuerdo con la tipología propuesta, interpretamos la situación actual de nuestro objeto de estudio en los siguientes términos.

Desde mediados de la década de 1980 la economía sinaloense, cuyo eje sigue siendo la horticultura de exportación, ha mostrado una tendencia hacia el estancamiento. Para explicar este fenómeno, debemos tomar en cuenta que, como apunta Messner (2002), los emplazamientos locales y las regiones, por un lado, se integran en cadenas globales de valor agregado y por otro, se enfrentan con estándares globales (técnicos, sociales, ambientales) establecidos por empresas, ONG, consumidores, gobiernos de diversos países, etcétera. De esta manera, el concepto de cluster atañe a la dimensión local-regional y se relaciona con el fenómeno de la competitividad sistémica, derivada de las relaciones entre las empresas y su entorno institucional.

La experiencia estudiada muestra, empero, que la dinámica de

En Sinaloa actualmente existe un cluster hortícola incompleto y estancado. Incompleto, porque están ausentes importantes agentes, su presencia es muy débil o bien sus nexos con los demás agentes del cluster son débiles o inexistentes. Estancado porque su impacto en la economía de Sinaloa no ha sido lo suficientemente fuerte para impulsar el crecimiento de los demás sectores

Sinaloa no puede ser explicada sólo a partir de la presencia o ausencia de un cluster, sino que deben ponderarse el grado de conectividad y el dinamismo económico del cluster. El primero puede explicarse por los comportamientos de los agentes presentes en el ámbito local, es decir, gobiernos, empresas nacionales o locales, instituciones y empresas multinacionales. Por su parte, el grado de dinamismo del cluster obedece tanto a factores intra-regionales, como globales. De gran peso es la posición del cluster en las cadenas globales de valor en términos de gobernanza, acceso a los mercados y tipo de estructura de la economía regional a la que pertenece el cluster. 
Por otra parte, dado que el cluster se ubica en un territorio y su estudio es relevante por su impacto en el desarrollo económico, social y ambiental del territorio, al evaluar su desempeño necesariamente hay que tomar en cuenta estos tres ámbitos.

Por todo lo anterior, desde la perspectiva del bienestar del territorio, en Sinaloa actualmente existe un cluster hortícola incompleto y estancado. Incompleto, porque están ausentes importantes agentes, su presencia es muy débil o bien sus nexos con los demás agentes del cluster son débiles o inexistentes. Estancado porque su impacto en la economía de Sinaloa no ha sido lo suficientemente fuerte para impulsar crecimiento de los demás sectores. Este estancamiento se expresa también en las mermas de las aportaciones de los diferentes sectores de la economía de Sinaloa a sus correspondientes nacionales, así como en la pérdida de competitividad de los principales productos de exportación de la entidad en el mayor de sus mercados.

A esto se agregan los fenómenos sociales y medioambientales vinculados con las prácticas hortícolas en Sinaloa. En lo social, un factor disfuncional son las precarias condiciones de trabajo de los jornaleros migrantes, incluyendo el trabajo infantil. Precarias en términos de retribuciones, duración de las jornadas, condiciones de traslado desde sus lugares de origen y de alojamiento en los campos agrícolas de Sinaloa, riesgos para la salud por el manejo inadecuado de productos tóxicos, por mencionar lo más evidente. ${ }^{26}$ Otro factor disfuncional son las prácticas agresivas y destructoras del medioambiente.

A la lista deben sumarse otros dos que no se derivan directamente de la actividad hortícola, sino que están relacionados con el pobre desempeño económico de Sinaloa en su conjunto. Uno es la emigración que está reduciendo demográficamente a la entidad (pérdida del llamado capital humano). Y el otro es el narcotráfico, atractivo para personas sin opciones viables dentro de la economía formal, pero con un profundo impacto negativo en términos de valores y de convivencia social. El miedo y la inseguridad en Sinaloa actúan

26. Debe enfatizarse que estamos hablando de las condiciones generales de los trabajadores, mismas que en algunas empresas son por completo diferentes. Es conocido que algunas importantes empresas hortícolas no emplean trabajo infantil, cuentan con clínicas, guarderías y escuelas para los hijos de los trabajadores y pagan salarios que no hacen necesario que los trabajadores manden al campo a sus hijos. Existen igualmente empresas que están combatiendo las plagas ecológicamente y muchas participan en el programa "Campo Limpio". Sin embargo, lamentablemente, todavía estos casos admirables están lejos de haberse generalizado. 
de forma destructiva sobre el tejido social, que constituye la esencia vital del territorio.

Lo anterior deja claro que los problemas relacionados con la existencia de un cluster hortícola en Sinaloa van más allá de lo económico, tanto por sus orígenes como por sus repercusiones y por lo tanto a las soluciones a dichos problemas.

Finalmente, desde la perspectiva territorial, a la situación de Sinaloa pueden aplicarse diversos conceptos, empleados por otros autores en casos similares, como son moderno enclave (Macías, 2010), territorio periférico (Delgado, 2002), o territorio disfuncional (Silva, 2004). Todos estos conceptos en esencia aluden al mismo problema y podrían ser utilizados probablemente de manera indistinta, sin embargo prefiero emplear el concepto de territorio desincrustado, porque retoma la tradición de Karl Polanyi y nos permite insertar la interpretación del fenómeno estudiado en un contexto no sólo económico, sino también político, social y global.

Además, la experiencia estudiada evidencia la cortedad del enfoque centrado sólo en el cluster para explicar el desempeño económico de una región. En Sinaloa faltan elementos para la constitución completa de un cluster, pero cabe preguntarse si el desempeño de Sinaloa sería mejor si estos elementos estuvieran dados. Si así fuera, desde luego que la competitividad sistémica de la entidad se elevaría, pero también hay que tomar en cuenta los otros dos vértices del triángulo económico propuesto por Messner, esto es, la posición que ocupa la horticultura sinaloense en las cadenas globales de valor correspondientes y su capacidad de adaptación a las exigencias impuestas por el mundo de los estándares globales.

Concerniente al primero de los elementos apuntados, debe reconocerse que la horticultura de Sinaloa se inserta en la cadena global de valor de la horticultura en uno de los eslabones iniciales, el de la producción y en cierta medida en el de la distribución, pero sólo hasta la colocación del producto en territorio estadounidense. Así, los agentes que ejercen la gobernanza en esta cadena no son los productores-exportadores sinaloenses, sino las empresas distribuidoras que en EU trasladan las mercancías a los principales centros de consumo y, de manera crecientemente relevante, las grandes cadenas de supermercados, que se están convirtiendo en los clientes principales de frutas y verduras frescas y que están imponiendo cada vez con más fuerza sus propias reglas del juego. Esta posición subordinada de los productores sinaloenses en la cadena global de valor de la horticultura poco se modificaría de existir 
un cluster local perfectamente articulado, ya que la horticultura practicada en Sinaloa arroja mercancías con escaso valor agregado y los horticultores finalmente reciben una parte mínima del precio final del producto. Esto se explica igualmente por el papel subordinado de la agricultura en la moderna economía global, centrada en actividades manufactureras y de servicios de alto valor agregado.

Tocante al segundo elemento, las presiones del mundo de los estándares globales, en particular los relativos a inocuidad alimentaria, seguirán presentes independientemente del grado de articulación de los elementos del cluster sinaloense. Aquí cobran singular relevancia las barreras sanitarias y fitosanitarias imponiéndose no sólo a Sinaloa, sino en todas partes, al comercio hortícola mundial.

Es por ello que el concepto de cluster nos lleva al terreno de la competitividad sistémica del territorio, pero no más lejos. Para evaluar el desempeño del territorio sinaloense en la economía global hay que complementar el análisis regional centrado en la conformación de clusters, con el análisis de las cadenas globales de valor y de la dinámica del mundo de los estándares globales.

Si bien es cierto que los resultados de nuestra investigación muestran la inexistencia de un cluster agroindustrial centrado en la horticultura de exportación en Sinaloa, debe apuntarse que han existido y existen esfuerzos de los propios horticultores por la constitución de un cluster, o por lo menos por el fortalecimiento del tejido empresarial cuyo eje es la horticultura de exportación. Estos esfuerzos son insuficientes ante la ausencia de otros impulsos que deberían provenir de los gobiernos municipales, estatal y nacional, así como de las instituciones de educación superior ubicadas en Sinaloa, que deberían avanzar en actividades de I\&D y en la formación de recursos humanos altamente calificados, en particular en los ámbitos más relevantes para los productores hortícolas.

Además, esta situación se ubica, por una parte, en un contexto de crisis económica mundial y, por otra, en una situación de dominio de un reducido número de empresas transnacionales en actividades clave para la horticultura, frente a las cuales resulta a las empresas nacionales imposible competir exitosamente. Otro elemento más lo constituye el desmantelamiento de la industria manufacturera en Sinaloa, por lo que no están presentes encadenamientos productivos para agregar valor a los productos hortícolas y las pocas empresas dedicadas a la conservación y procesamiento de frutas y verduras son una excepción que evidencia la crítica situación imperante. 
Finalmente, en Sinaloa, a diferencia de otras experiencias donde los clusters se forman sobre la base de pequeños y medianos productores, existe una estructura oligopólica del mercado y muchas de estas grandes empresas que dominan el mercado, debido a la escala y diversidad de sus operaciones, incluyendo empacado, transportación y distribución, se convierte en un centro de gravitación para otras unidades de menor tamaño, pero sin que exista una integración a nivel regional y mucho menos alguna homogeneidad entre los productores, debido a grandes diferencias de tamaño.

En Sinaloa no puede hablarse - como en Almería, por ejemplo- de la existencia de una red socio-institucional que integre a la mayoría de los agentes susceptibles del sistema productivo, como son las administraciones locales y regionales, las distintas asociaciones empresariales, los centros de investigación y de formación, etcétera. ${ }^{27}$

Todo indica que en Sinaloa no existe un sistema, distrito o cluster agroindustrial. ${ }^{28}$ Sí podría hablarse de especialización productiva, término empleado por Silva (2004: 24) para referirse a Huelva, que, por otra parte, tendría en común con los sistemas agrocomerciales andaluces, el llegar a ser un modelo insostenible, basado en disfunciones ambientales, en la precariedad laboral y, en ocasiones, también en la conflictividad social. Esto último, porque frente al encarecimiento de los insumos y la caída de los precios de los productos, debida con frecuencia al exceso de oferta, el empresario trata de equilibrar su situación presionando los salarios a la baja, lo cual es posible en especial cuando se trata de jornaleros migrantes (Silva, 2004: 28).

Resta proponer una explicación específica para el caso aquí analizado. ${ }^{29}$

27. Sobre el interesante caso de Andalucía, cuyos paralelos con Sinaloa son evidentes — como lo son también sus diferencias-, véanse los trabajos pioneros de Caldentey (1998) y el de Ferraro (2000), especialmente amplio, así como el de Aznar (2006), quien tiene la virtud introducir el tema de la competencia marroquí, así como desde una perspectiva con mayor énfasis en lo social, los de Delgado (2002, 2006) y el de Silva (2004), que permite entender las discrepancias entre los autores que han estudiado las experiencias hortofrutícolas de Andalucía.

28. Como alternativa algunos estudiosos han propuesto hablar de un distrito o cluster agro-comercial, pero incluso en este caso están ausentes las redes socio-institucionales de apoyo a dicho sistema.

29. Para poner más de relieve estas deficiencias de Sinaloa, es pertinente contrastar este caso con la reciente experiencia del el proyecto denominado Tecno-Parque Hortícola Fidesur-Sandia, en el estado de Nuevo León, a 220 kilómetros, tres horas por carretera, de la capital del estado y anteriormente una zona marginada de gran pobreza, sí es un buen ejemplo de un cluster agrícola, donde el propósito es obtener hortalizas frescas, sobre todo tomate cultivado en invernaderos, $50 \%$ para exportación y $50 \%$ para el mercado nacional. En el proyecto, diseñado en mayo de 2007 y puesto en operaciones en marzo de 2008 sobre una superficie de 65 


\section{Causas probables de la existencia de un cluster incompleto y estancado en Sinaloa}

Para consolidar su posición en el mercado estadounidense, los horticultores sinaloenses han realizado grandes esfuerzos y alcanzado logros innegables. Por ejemplo, la creación y posterior expansión de Agroindustrias del Norte; el establecimiento de empresas distribuidoras en Estados Unidos, por parte de los propios productores; la creación, en 1932, de la organización de horticultores más importante del país, la Confederación de Asociaciones Agrícolas del Estado de Sinaloa. ${ }^{30}$ Sin embargo, todavía existen debilidades por parte de los productores, como son concentrar su atención en los aspectos productivos, descuidando la organización empresarial y gremial, las prácticas gerenciales, así como las estrategias de venta, manejo postcosecha y el transporte de mercancías a los Estados Unidos (Gaxiola, 2007).

Al mismo tiempo es notorio el contraste entre la prosperidad de Sinaloa entre 1960 y la década de 1980, cuando se proyectaba como un polo de desarrollo regional y la caída experimentada desde los años noventa, que ha llevado al estado de los once ríos a los rangos más bajos del país en cuanto a ritmo de crecimiento económico y capacidad de generación de empleo. Estos rezagos pueden explicarse por los cambios en la orientación del modelo de crecimiento, ocurridos en el país durante la década de 1980, que afectaron profundamente a Sinaloa, bloqueando su desarrollo agrícola y destruyendo la poca capacidad agroindustrial hasta entonces lograda.

Desde entonces se ha contraído su sector primario, el sector servicios se ha expandido desproporcionadamente y el sector industrial ha caído en un franco estancamiento; fenómenos estrechamente vinculados con las políticas públicas erróneamente instrumentadas en la entidad (López Cervantes, 2007). Cierto que el comportamiento de la agricultura no ha sido el deseable, pero también han tenido un pobre desempeño los servicios y la industria. Así, los procesos negativos que padeció la agricultura no fueron suficientemente compensados por tales actividades, en gran parte porque los daños a la agricultura afectaron al proceso de acumulación en su conjunto, pues ésta

hectáreas y con 55 invernaderos, han participado el gobierno estatal, el gobierno federal, la Universidad Autónoma de Nuevo León y 55 familias de productores, organizados en seis sociedades. El proyecto empezó a rendir frutos en el año 2008, cuando se enviaron sus primeras exportaciones a Estados Unidos.

30. Sobre la CAADES es ya un clásico el libro de Grammont 1990. 
era fuente de excedentes invertidos en áreas económicas localizadas en las ciudades (Trujillo y Gaxiola, 2010).

Antes de la apertura, Sinaloa carecía de una base industrial más allá de la industria de alimentos, y era fuerte beneficiaria de políticas públicas que asumían los costos de transporte de materias primas agrícolas a los principales mercados del país. Con la apertura económica, tales costos se volvieron críticos y evidenciaron las desventajas de Sinaloa. Esto bloqueó el desarrollo industrial y lesionó su competitividad en la producción de alimentos, pues no se hicieron las inversiones en obras de infraestructura necesarias para mejorar su comunicación con el resto del país y con Estados Unidos.

A todos los aspectos anteriores habría que añadir uno más, relacionado con la conducta empresarial. Los agricultores sinaloenses conocen el manejo tecnológico de su actividad y están dispuestos a adoptar nuevas tecnologías, haciendo las inversiones necesarias. No obstante esto, al ser la agricultura una actividad azarosa y de alto riesgo, especialmente en hortalizas frescas, el productor es individualista, está acostumbrado al riesgo, espera eventuales ganancias elevadas y por lo tanto tiene cierta mentalidad de apostador. Esto ha dificultado el traslado de capital agrícola hacia la industria, la cual supone flujos más estables, pero también de menor magnitud, y tiempos de espera más largos para la acumulación y obtención de altas ganancias. Esta actitud ha dificultado también la disposición de asociación entre empresas.

Quizá hacia los años setenta ya existiera un sistema productivo local (Carrillo, 2009), e incluso un distrito agro-comercial (Frías, 2009), cuyo eje era la horticultura de exportación, pero en el que participaban numerosas empresas industriales y de servicios vinculadas a la agricultura, pero entonces habría que explicar qué ocurrió en las décadas siguientes, y que condujo a una horticultura exportadora todavía fuerte pero en proceso de debilitamiento, ubicada en un entorno económico en creciente deterioro, con un sector terciario hipertrofiado y un sector agroindustrial no sólo insuficiente, sino víctima de un largo proceso de desaparición. ¿Por qué el sistema productivo local y el "distrito agro-comercial" no se consolidaron y, mucho menos, se desarrollaron en las décadas subsiguientes? Ésta historia todavía está por escribirse y sólo podemos apuntar algunas hipótesis.

Uno. Apertura comercial unilateral desde el ingreso de México al GATT en 1986 y puesta en vigor del TLCAN en 1994.

Dos. Crisis de la cartera vencida en la agricultura mexicana a raíz de la crisis de 1995 y de la desaparición de la banca agropecuaria de desarrollo. 
Dramática reducción de los créditos a la agricultura procedentes tanto de la banca comercial como de la banca de desarrollo, a partir de $1994 .{ }^{31}$

Tres. Reformas estructurales (1982-1988): ajuste de las finanzas públicas, liberalización de los mercados financieros, apertura comercial, privatización de las empresas públicas, desregulaciones, reducción de la intervención del gobierno en la economía en general y en particular en la agricultura.

Cuatro. Ante la ausencia de una política nacional de fomento a la investigación para la creación de semillas mejoradas, los horticultores pasan a depender completamente de las grandes empresas transnacionales que desarrollan desde hace décadas las tecnologías adecuadas para la obtención de dichas semillas. Estas empresas, gracias a la apertura comercial, encuentran mayores facilidades para establecer sucursales en México y en particular en Sinaloa.

Cinco. Gracias a la apertura comercial las grandes empresas transnacionales productoras de maquinaria agrícola encuentran facilidades para establecerse en México.

Seis. Los clusters agro-industriales no son un resultado automático del mercado, sino que exigen la presencia del Estado como promotor y organizador de iniciativas tendientes a la formación de tales agrupamientos, cuyo propósito principal no la elevación de la rentabilidad de empresas individuales, sino la promoción del desarrollo regional, apoyado en una combinación adecuada de políticas sectoriales y políticas públicas locales.

Para finalizar, resta sólo poner énfasis en la necesidad de analizar la experiencia de la horticultura de exportación desarrollada en Sinaloa desde una amplia perspectiva, que combine la dinámica propiamente local con la del mundo global, que integre elementos económicos, con otros de tipo social, político y cultural. Sólo de esta manera podremos comprender nuestra realidad y contar con herramientas útiles para construir un mejor futuro. my

31. En el año 2004 los créditos mencionados equivalieron aproximadamente a un quinto de los concedidos en 1994, según datos del Banco de México (www.banxico.gob.mx). En la década mencionada el crédito agropecuario se fue reduciendo a una tasa anual de $16.3 \%$. Todavía en la actual década la cartera vencida agrícola sigue siendo considerablemente alta. 


\section{Referencias}

Asociación Mexicana de la Industria Fitosanitaria, AC, Informe Anual 2008, México, 2008. Véase también la página electrónica de la asociación en: www.amifac.org.mx.

Aznar Sánchez, J. A., La competencia entre la horticultura intensiva de Marruecos y España, Cizur Menor, España, Cajamar, Thomson Civitas, 2006.

Bajo, A., "La vinculación como componente estratégico en la formación de clusters en las regiones del estado de Sinaloa, desde una perspectiva de la economía del conocimiento". Congreso Iberoamericano: Ciudadanía y Políticas Públicas en Ciencia y Tecnología, Madrid, España, febrero 5-8, 2008.

Beraud Lozano, J. L., Galindo Reyes, J. G. y Covantes Rodríguez, C. (coords.), Jornaleros y medio ambiente: los agroquímicos en la agricultura sinaloense, Culiacán, México, Universidad Autónoma de Sinaloa, 2008.

Caldentey Albert, P., "El distrito agro-comercial del campo de Dalías (España)", Agroalimentaria, 1998, núm. 7, pp. 21-28.

Carrillo Rojas, A., "Articulación productiva de empresas y productores hortícolas en el valle de Culiacán: la situación actual en perspectiva histórica", Romero Ibarra, M. E. y Carrillo Rojas, A. (coord.), Empresa y agricultura comercial en el Noroeste de México. Historia económica y tendencias actuales, México, Universidad Nacional Autónoma de México, 2009, pp. 375-419.

Comisión para Investigación y Defensa de las Hortalizas (CIDH) 2009, Cierre de ciclo de hortalizas 2008-2009. Culiacán, Sinaloa, en: http://www.cidh. org.mx (revisado en febrero 7 de 2010).

CropLife Latin America, Una visión compartida. Más de 10 años trabajando por el Desarrollo Agrícola de América Latina, Sao Paulo, 2002.

Dávila Flores, A., "Los clusters industriales del noreste de México (1993-2003). Perspectivas de desarrollo en el marco de una mayor integración económica con Texas", Región y Sociedad, vol. xx, núm. 41, 2008, pp. 57-88.

Delgado Cabeza, M., Gavira Álvarez L. "Agricultura y trabajo rural en la globalización", Revista Española de Estudios Agrosociales y Pesqueros, 2006, núm. 211, pp. 21-61.

Delgado Cabeza, M., "Andalucía en la otra cara de la globalización. Una economía extractiva en la división territorial del trabajo", Sevilla, España, Megablum, 2002. 
Díaz Coutiño, R. "Sinaloa: la escasez de agua y la variabilidad climática", en Maya Ambía C, Aguilar Soto O. (coords.), Sinaloa en la globalización. Costos ecológicos, sociales y económicos, México, Plaza y Valdés, 2007, pp. 71-101.

Díaz Coutiño, R., Los límites locales del crecimiento. Sinaloa en la dimensión global, Culiacán, Sinaloa, Universidad Autónoma de Sinaloa, 2004.

Dussel Peters, E., Territorio y competitividad en la agroindustria en México. Condiciones y propuestas de política para los clusters del limón mexicano en Colima y la piña en Veracruz. Municipio de Isla, Secretaría de Economía, CEPAL, Universidad de Colima, Plaza y Valdés, México, 2003.

Elizalde, R. Entrevista 11 de diciembre de 2009. Comisión para la Investigación y Defensa de las Hortalizas. Culiacán, Sinaloa.

Espinosa García, J. A., "Perfil de la industria alimentaria de Sinaloa”, en López Leyva et al., Los sistemas regionales de innovación. Un acercamiento al caso de Sinaloa, Culiacán, Sinaloa, México, Universidad Autónoma de Sinaloa, 2002, pp. 229-282.

Ferraro García, F. J. (coord.), El sistema productivo almeriense y los condicionamientos hidrológicos, Madrid, Caja Rural de Almería, Civitas Ediciones, 2000.

Figueroa Elenes, R., "La industria manufacturera sinaloense en los contextos nacional y mundial”, en López Cervantes, G. (coord.), Evaluación económica y social de Sinaloa 1990-2002, Culiacán, Sinaloa, México, Universidad Autónoma de Sinaloa, 2003, pp. 161-223.

Frías Sarmiento, E., "La exportación del tomate sinaloense y su valor comercial: 1920-1956”, en Romero Ibarra M. E. y Carrillo Rojas, A. (coords.), Empresa y agricultura comercial en el Noroeste de México. Historia económica y tendencias actuales, México, Universidad Nacional Autónoma de México, 2009, pp. 107-141.

Gaxiola Carrasco, H. E., "Sinaloa: tecnología, agua y competitividad en su horticultura”, en Maya Ambía, C. J. y Aguilar Soto, O. (coord.), Sinaloa en la globalización. Costos ecológicos, sociales y económicos, México, Plaza y Valdés, 2007, pp. 197-228.

Gaxiola Carrasco, H. E. y Trujillo Félix, J. D., "Los ajustes en la agricultura de Sinaloa”, en Maya Ambía, C. J. y Ponce Conti, Y. C. (coords.), Apertura comercial y (sub)desarrollo regional. La experiencia de Sinaloa, México, Plaza y Valdés, 2010, pp. 49-71.

Gobierno del Estado de Sinaloa. Quinto informe del gobernador Jesús Aguilar Padilla. Culiacán, Sinaloa, 2009, en: http://www.sinaloa.gob.mx. 
Gómez Brindis, J. G., Semillas hortícolas. Catalogo Nacional de Variedades, tomo II, México, edición del autor, 2010.

Grammont, H. C., Los empresarios agrícolas y el estado: Sinaloa 1893-1984, México, Universidad Nacional Autónoma de México, 1990.

Grammont, H. C. y Lara, S., Encuesta a hogares de jornaleros migrantes en regiones hortícolas de México: Sinaloa, Sonora, Baja California y Jalisco, México, Universidad Nacional Autónoma de México-Instituto de Investigaciones Sociales, 2004.

Guerra, M. T., Los trabajadores de la horticultura sinaloense, Culiacán, Sinaloa, Universidad Autónoma de Sinaloa/Comisión Estatal de Derechos $\mathrm{Hu}-$ manos, 1998.

Halkin, Alexandra, Migrar o morir: jornaleros agrícolas en los campos tóxicos de Sinaloa, 2008, en:http://www.youtube.com/watch?v=WLI5eRZNkmw.

INEGI, El sector alimentario en México, edición 2008, en: http://www.inegi. org.mx/prod_serv/contenidos/espanol/bvinegi/productos/integracion/ sociodemografico/SAM/2008/sam2008.pdf.

INEGI, Gobierno del Estado de Sinaloa, Anuario Estadístico de Sinaloa 2009, Aguascalientes, 2009.

INEGI, Anuario de estadísticas por entidad federativa, Aguascalientes, 2009.

Ketels, Christian H. M., The Development of the cluster concept-present experiences and further developments, 2003, en: http://www.isc.hbs.edu/ pdf/Frontiers_of_Cluster_Research_2003.11.23.pdf.

López Barraza, L. M., "La gobernancia de las distribuidoras en la cadena hortícola de valor Sinaloa-Estados Unidos”. Tesis doctoral en Economía, Universidad Autónoma de Sinaloa, México, 2008.

López Cervantes, Gerardo, "El contexto económico del desarrollo rural de Sinaloa, 1994-2005”, en Maya Ambía, C. y Aguilar Soto, O. (coord.), Sinaloa en la globalización. Costos ecológicos, sociales y económicos, México, Plaza y Valdés, 2007, pp. 45-70.

Macías, A., "Empresarios y dinámicas extraterritoriales en la agricultura de hortalizas en México. El caso Sayula, Jalisco", en Maya Ambía, C. y Hernández Moreno, M. C. (coord.), Globalización y sistemas agroalimentarios, México, Juan Pablos Editor, 2010, pp. 125-154.

Mandang, T. y Wiryokusumo, H. (s/d), Development of Agro Industrial Cluster (AIC) in Indonesia. An investment opportunity, en: http://kdei-taipei.org/ artikel/investasi/Agroindustrial_Cluster.pdf. 
Mares, D. R., La irrupción del mercado internacional en México. Consideraciones teóricas y estudio de caso, México, El Colegio de México, 1991.

Medina Cázares, E., El sector de alimentos en Sinaloa. El reto de consolidar el liderazgo, Consejo para el Desarrollo Económico de Sinaloa, Unidad de Estudios Económicos. Culiacán (México), 2006, en: http://s3.esoft. com.mx/esofthands/include/upload_files/18/Archivos/Sector\%20de\%20 Alimentos\%20en\%20Sinaloa.pdf.

Messner, D., The Concept of the "World Economic Triangle", Global Governance Patterns and Options for Regions. IDS Working Paper núm. 173, Institute of Development Studies, Brighton, 2002.

OECD, Policy Brief, mayo, 2007, en: http://www.oecd.org/dataoecd/34/22/38653705.pdf.

OECD, 2001, Innovative Clusters. Drivers of National Innovation Systems, Enterprise, Industry and Services, París, OECD Publications.

Posadas, F., Identidad y voluntad colectiva de los trabajadores agrícolas, Culiacán, Sinaloa, Consejo Nacional de Ciencia y Tecnología/Universidad Autónoma de Sinaloa/Consejo Estatal de Ciencia y Tecnología, 2009.

Retamoza Gurrola, A., El Estado y la industrialización en Sinaloa, Culiacán, Sinaloa, México, Universidad Autónoma de Sinaloa, 1994.

Sagarpa, Fidesur, Tecno-Parque Hortícola Fidesur-Sandia, marzo 2009. http:// www.siap.gob.mx/ForoIX/Ponencias/Panel5/TecnoParqueFIDESUR.pdf.

Sánchez Saldaña, K., "Los niños en la migración familiar de jornaleros agrícolas", en Del Río N. (ed.), La infancia vulnerable de México en un mundo globalizado, México, Universidad Autónoma Metropolitana/Unicef, 2000, pp. 79-94.

Silva Pérez, R., "Redes socio-institucionales, dinámica innovadora y disfunciones territoriales en los sistemas agrocomerciales andaluces", Revista de Estudios Regionales, 2004, núm. 70, pp. 13-40.

Trujillo Félix, J. D. y Gaxiola Carrasco, H. E., "Economía y agricultura en Sinaloa", en Maya Ambía, C. J. y Ponce Conti, Y. C. (coords.), Apertura comercial y (sub)desarrollo regional. La experiencia de Sinaloa, México, Plaza y Valdés, 2010, pp. 19-47.

Yúnez-Naude, A., Evaluación externa del Programa de Atención de Jornaleros Agrícolas, México, El Colegio de México/Secretaría de Desarrollo Social del Gobierno de México, 2005, en: http://precesam.colmex.mx.

Zazueta Medina, A., "La banca y el financiamiento al sector agropecuario en Sinaloa 1995-2004”. Tesis de Maestría en Economía Regional. Universidad Autónoma de Sinaloa 2006. 